\title{
The Study of Guide Policy to the Internet Public Opinion in Micro-era Higher Vocational College
}

\author{
Liu Jiqiang ${ }^{1,2}$ \\ ${ }^{1}$ School of Marxism Education, University of Electronic Science and Technology, Chengdu, \\ Sichuan 611731; \\ ${ }^{2}$ Sichuan College of Architectural Technology, Deyang, Sichuan 618000 \\ aemail, bemail,
}

Keywords: Higher Vocational Colleges; New Media; Crisis; Internet Public Opinion; Guide

\begin{abstract}
The crisis in new media environment is a new normal of the social transformation. With the growing popularity of micro blog, we chat and other new media, the micro era is coming. When emergencies occur in higher vocational colleges, vocational colleges public opinion in new media environment has a new propagation characteristics that vocational colleges managers should grasp the crisis in mental crisis communication and public law, emphases on the media guide construction of regulatory mechanisms, and enhance the ability of guiding to the public opinion under the new media environment.

Nowadays, with the advancement of information and network technology, the micro-channel micro era characterized by we chat, micro blog and "Mobile Internet + IM" is coming. China is in the social transition period, various crises frequently happened, higher vocational colleges how to deal with crisis events properly and guide public opinion, to strengthen guide policy to public opinion in the new media environment, has become an important part of social management innovation in the Higher Vocational Colleges.
\end{abstract}

\section{The Analysis about Characteristics of Micro-Era Mass Media}

Interactivity. New media makes the senders and the audiences use a variety of channels to complete the information exchange, especially in the field of public opinion problems. In addition, due to the existence of heated discussion based on the new media and instant feedback mechanism, it has a significant impact compared to traditional media.

Effectiveness and Convenience. In recent years, blog, micro blogg and other new media as a platform have been recognized by the people and sought after. The public can very easily understand the social dynamics in the first time.

The Coexistence of Decentralized Multi-Center. In the new media environment, the introduction of digital and network technologies, "no power center" of information dissemination channels are built up, where these individuals and social groups live, are able to send a message and receive information and can release message in discourse "Center".

\section{Analysis of Communication in New Media Network Environment About Public Opinion in Higher Vocational Colleges}

With the rapid development of information technology, the micro blog, we chat and other mobile client-based new media with its unique features and charm strongly attracted the student population. Public opinion in the incident spread, the crisis event in Higher Vocational Colleges has exacerbated their degree of activity and participation, consequently their behavior in the crisis communication 
process becomes more complex.

The Phenomena of Behavioral in the Collection of "Crisis Sensation". Different from general information dissemination, the student population in Crisis situations is not only the recipient of information, but also the "stakeholder", so that there will be characteristics of symbol disorder, meaning twisted, damage to the interests and values of the of alienation in crisis communication. The media scholar Robert Heath named the change and confusion in crisis situations "Crisis Sensation". Meanwhile, he called the abnormal collection of social phenomenon under certain stimuli conditions "a collection of behavior." The famous social psychologist Gustave Le Bon believes that in times of crisis, people's thoughts and feelings easily go into the emotional collective unconscious state by implication and infection. While this kind of outbreak of emotions often hidden powerful destruction which leads people to be impulsive, out of control and do mass events. Crisis is a fuse of collection behavior while network communication exacerbates the possibility of collection action.

"Spiral of Silence" Effect under "Similar Force". When people decide to take some action, they always consider the impact it brings not only to individuals, but also to the expectations of the population. This is what we called "peer pressure" or "the same force". During the crisis, people are subjected to similar pressure was particularly notable and fear and anxiety make people turn to accept support groups. Similarly, German sociologist John von Neumann raised the "spiral of silence" theory. It has three features. One is the formation of public opinion is the results of interaction of mass communication, interpersonal communication and people cognitive on the "Opinions environment"; The other is to emphasize prompt advice through mass media easy to be treated as "advantage" comments cognition; Finally, the pressure brought by environmental awareness or sense of security will cause people "inferior views silence" and "advantage opinions loudly" consequently it forms a spiral extended process and ultimately leads to social life generate overwhelming public opinion. Screw mechanism expressed views result in a crisis of sided public opinion. The powerful force of "Spiral of silence" makes higher vocational colleges caught in a fair hearing of the situation, suffered losses in the public. It is obvious that the "Spiral of Silence" effect under "similar force" in the crisis is also likely to play an active role.

"Selective Engagement" and "Confrontational Interpretation" of the Student Population in the Crisis. The concept of "selective engagement" is raised byPaul Lazarsfeld after "Iri investigation", it suggested that the audience is not meant to treat any dissemination of content indiscriminately, but inclined to "choose" those with their stand, consistent attitude to the content of the contact. "Against Interpretation" is proposed by Stuart Hall, it meant that the audiences understand the information of media in an opposite way. The explosion of information makes college students do choice more freely, also makes the student population more vulnerable to a loss situation. The overload Information is likely to exacerbate fears of college students, at this time, college students tend to be selectively contacting and accept that it can get a certain sense of information security, and to exacerbate its fears or its intrinsic cognitive contrary opinion make a "confrontational interpretation." Thus, in this very state of crisis communication propagation scenario "Flowers" information precisely set the way for public relations crisis in higher vocational colleges.

\section{The Bottleneck Analysis of Emergency Public Opinion Guide in the New Media Environment}

The Weak Capacity of Emergency Public Opinion Guide. In recent years, due to historical and practical factors, the development of social order in China is facing an unprecedented challenge. The imbalance of social psychological, weight loss of benefits and other unexpected events 
seriously affected the normal social order. The number of incidents is rising. Grasping the dynamic of public opinion and guiding public opinion timely, comprehensive and effectively are becoming the major issues of the relationship between higher vocational colleges and social stability. However, even if China has entered the "risk society", the response of the higher vocational colleges, social organizations and individuals to emergencies still shows a loss because of the lack of training in the new media context and the effect is not satisfactory.

The Absence of Construction Awareness to New Media. In the current period, the mobile Internet, we chat, micro blog and other new media and digital platforms continue to gain popularity. The public can take this convenient and efficient expression of public opinion to participate in social and political life. But some vocational colleges' websites or the official forums do not recognize characteristics such as timeliness and openness of network public opinion in the aspects of agenda-setting, language selection, and interactive reports. In addition, the way to new media is simple and less efficient, which makes it difficult to guide public opinion to achieve positive results.

The Lagging Concept of Public Opinion Guide. New media belongs to new things, but is not fundamentally replaced by traditional media. Consequently, it is important to combine two kinds of media to respond to the emergencies. The micro blog, we chat, the Internet and traditional newspapers, magazines, radio and broadcast should work together to build three-dimensional media guidance mechanism to achieve a better guide public opinion results. But in actual operation, traditional media and new media due to the imbalance and differences in levels of development and the importance often conflicts, both of them are difficult to form a force of public opinion, so that the effectiveness of public opinion guide is not enough.

\section{The Method of Higher Colleges Public Opinion Guide in the New Media Environment}

Grasp Dissemination and Psychological Laws, Proactive and Timely Communication. The famous crisis management "3T" principle, namely "Tell your own tale”, "Tell it all” and “Tell it fast”, was raised by the British crisis PR expert Rogers. It helps us to point out the principles for the crisis information communication and public opinion guide specific practices. Being active and communicate as soon as possible means that vocational colleges should publish information in the first time of crisis, with the fastest speed to seize the initiative to set the agenda. The first time is not only a synonym for information dissemination of "speed", but also a monitoring force to deter the proliferation of bad information. Therefore, the first time publish information determines whether vocational colleges can occupy the high ground communication and crisis public relations is the first step. The crisis public relations crisis in higher vocational colleges provide a severe test of colleges for the first time released information is not perfection but for the fast and true, proactive communication, communication as soon as possible.

Play "Opinion Leaders" Role, and Actively Guide Public Opinion. In communication perspective, the "opinion leaders" was first proposed by a media scholar Paul Lazarsfeld. Higher Colleges opinion leaders as media messages relay and filtration areas have an important influence on mass media effects. Higher Colleges. Trust, influence, a common system of symbols and other factors make people more willing to get information from opinion leaders there, so they are "gatekeeper". This means that if a crisis in higher vocational colleges can find opinion leaders, and effectively play their role, can accurately grasp public opinion, to effectively guide public opinion and it must be in the front, the real, objective under the premise. In the network, we can through the selection of the best friends of the altar, moderators, etc., entrust them to a particular office and other ways to train a group with high political quality, reasoning ability of Internet users act as opinion leaders, to strengthen the authority of views through their organization comments 
controversial views, opinions and other methods to eliminate the error guide "affect the flow".

Integration with Traditional Media, Expanding the Media Guide Together. Integration of new and traditional media is an inevitable trend for communications industry to "win-win". Neumann communication scholars have risen: the majority of the media reported the contents of a similar performance has resonating effect, the same continuity and dissemination of information generated cumulative effect of repeat performance. Internet media and traditional media can guarantee the expression of public opinion and the media set the agenda by mutual rationalization to the maximum extent. Network for its interaction media and equality can quickly deliver voice of the people and safeguard the democratic nature of public opinion. Traditional media to rely on its high-quality production team and reliable information source established credibility have a better effect than the average of new media. Open new media that the guide online public opinion have been a crisis public relations problem, the network makes a lot of noise on the public the truth no agreement, then the traditional media agenda setting by selecting the agenda and the agenda of the importance of network arrangements affect the student population agenda construction to promote the evolution of the network of public opinion which is reasonable in the right direction. Some vocational colleges established campus New Media Alliance is the integration of vocational colleges and traditional media to expand the force of public opinion so as to guide a useful attempt and practice.

Establish Contingency Plans for Higher Vocational Colleges to Strengthen the Network of Crisis Intervention. The continuous development of new media and frequent occurrences of crisis events decided to establish long-term mechanism for vocational institutions network public opinion guide to make public relations crisis into daily communication activities, to occupy the commanding heights of crisis spread, to grasp opportunities in the media guide. Students today are "90"s and the "post-95"s, their self-awareness of rights is growing. Some of them will solve the problems which are long-term existed on the campus through regular new media for help, complaining, broking or complaints. In the meantime, management of higher vocational colleges should pay attention to public opinion collection. As for higher vocational colleges, the key to higher vocational colleges in the event of winning a crisis is to make good crisis communication plans, to establish crisis response mechanism. A good and effective contingency plan prepared in advance will play a multiplier effect.

In short, the development of human society determines that the crisis is difficult to predict. With the growing popularity of micro blog, we chat and other new media channel, the micro era is coming. Crisis in the new media environment will be a new normal in the social transformation. The public opinion "in a crisis" in higher vocational colleges must also be set in a new blueprint. The higher vocational colleges should grip both technology and the humanities coping strategies and look forward to the fact that the value of the return of the "crises" as in the development of "chance".

\section{Acknowledgements}

Fund Project: Project of Education Department of Sichuan Province "On the Guiding Strategies of Micro-era College Network Public Opinion guidance" (project number: 14SB0478), project of Ideological and Political Education Researching Association of Sichuan Province "On the Network Moral Education of Higher Vocational Students" (Project No. SZ2015115), project of Sichuan College of Architectural Technology "From the Core Values Perspective of Cultivation Higher Vocational College Students"(No. 2016022) and "On the Construction of Ideological and Political Platform Based on the E-Class in Colleges"(No. 2016019). 


\section{References}

[1] Guo Qingguang. Communication Tutorial[M]. China Renmin University Press, 1999

[2] Zhang Lili. From Crisis Communication Perspective of Emergencies Spread in the New Media Environment[D]. Suzhou University, 2010

[3] Gao Fangfang. The Research of Public Opinion Guide and Control Mechanism of Emergency under the New Media Environment[J]. School Party and ideological education, 2015 (4) 